\title{
Elimination of self-punitive behavior with a novel stimulus and safety signal
}

\author{
DENNIS J. DELPRATO and L. ALLEN CAROSIO \\ Eastern Michigan University, Ypsilanti, Michıgan 48197
}

\begin{abstract}
After escape training in an alley, rats received either nonpunished (NP) or punished (P) extinction. During extinction, NP and $\mathrm{P}$ groups received (a) a novel tone in the startbox, (b) a tone in the start- and goalboxes (the tone had been presented in the goalbox to these subgroups during acquisition-safety signal condition), or (c) no tone. Punishment produced greater resistance to extinction than nonpunishment (self-punitive effect) only under no-tone conditions. The elimination of self-punitive behavior with novel tone and safety signal treatment is consistent with the hypothesis that self-pur:itive running is motivated by excessive fear.
\end{abstract}

Self-punitive running is observed when responsecontingent aversive stimulation, e.g., shock, is less effective than nonpunished control treatment in eliminating responses that have been established by escape or avoidance training in a runway (Brown, 1969; Melvin, 1971). While most research to date on the self-punitive effect has focused on the identification of variables that optimize the phenomenon, some studies do reveal treatment conditions that may be effective in reducing self-punitive behavior. For example, self-punitive running has been reduced when an 18-min rest interval was interpolated between acquisition and extinction trials (Martin, 1969), by a period of response prevention in the start area (O'Neil, Skeen, \& Ryan, 1970), and when another rat was placed in the start region (Walker, Williams, \& Martin, 1974). The efficacy of these treatments is understandable from the MowrerBrown interpretation (Brown, 1969; Melvin, 1971) of self-punitive running, because all should effect reductions in conditional fear, a hypothesized source of motivation of behavior.

Consideration of variables that have been associated with diminutions of fear and avoidance reveals two additional treatments that should eliminate self-punitive behavior-novel auditory stimulation and safety signals. Baum and Gordon (1970) and Henderson (1973) have clearly shown that novel stimuli (loud buzzer and tonal stimulus, respectively) attenuate fear behavior and interfere with avoidance responding. Since the Mowrer-Brown hypothesis maintains that self-punitive behavior is motivated by excessive levels of fear, introduction of a novel tone in the start region should reduce self-punitive behavior. This hypothesis was tested in the present experiment.

Cues that predict a period of nonshock against a background of shock are referred to as safety signals (Bolles \& Moot, 1972), and several investigations have shown that these stimuli inhibit fear-motivated behavior (see review by Bolles \& Moot, 1972). Therefore, if self-punitive running is motivated by fear, such behavior should be reduced if a safety signal is presented in the start area prior to each response occurrence. A procedure similar to that reported by Weisman, Denny, Platt, and Zerbolio (1966) was used to test this second hypothesis in the present research. Weisman et al. (1966) found that a response-contingent safety signal facilitated extinction of a unidirectional avoidance response when the signal was presented in the shock area during extinction trials. The prediction here is that groups receiving a tone (safety signal) in the goalbox of the alley during escape acquisition and extinction and in the startbox during extinction should show less self-punitive running than standard groups not exposed to a safety signal.

\section{METHOD}

\begin{abstract}
Subjects and Design
The subjects were 72 male rats of the Sprague-Dawley strain, with weights ranging from 300 to $432 \mathrm{~g}$.

Twelve rats were assigned to each of six gioups formed by the factorial combination of punishment (nonpunishment vs. punishment) and tone (standard no-tone condition, novel-tone group, and safety signal treatment) variables.
\end{abstract}

\footnotetext{
Apparatus

The apparatus consisted of a stratght alley $(121.9 \times 11.4 \times$ $20.3 \mathrm{~cm})$, an oversized goalbox $(37.5 \times 30.5 \times 25.4 \mathrm{~cm})$, and a two-compartment trapdoor startbox The lower compartment of the startbox was an extension of the alley, and 11 measured $30.5 \times 11.4 \times 20.3 \mathrm{~cm}$. The upper compartment measured 24.1 $\times 11.4 \times 20.6 \mathrm{~cm}$. The trapdoor floor was hinged along the left edge $15.2 \mathrm{~cm}$ above the startbox floor. The floor of the startbox and alley was constructed of $.3-\mathrm{cm}$-diam stainless steel rods spaced $1.3 \mathrm{~cm}$ apar', center to center The wall of the startbox and alley consisted of white plywood The walls and floor of the goalbox were constructed of wood painted a flat black. A guillotune door that was lowered to prevent retracing separated the alley from the goalbox. All sections of the apparatus were covered with hinged Plexiglas lids, and the goalbox lid was covered with ruby red plastic.
} 


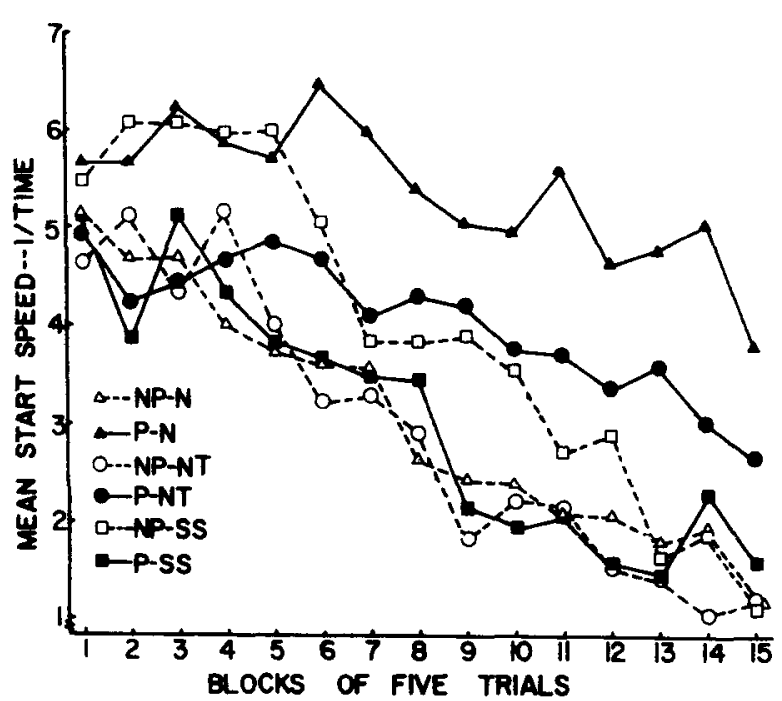

Figure 1. Mean start speeds over blocks of five extinction trials.

The shock source was a Model 113-04 Lehigh Valley Electronics constant current shocker set to deliver $1.0-\mathrm{mA}$ scrambled shock. Speakers in the startbox and goalbox enabled presentation of a $4,000-\mathrm{Hz}$ tone at $86 \mathrm{~dB} \pm 1$ re $.0002 \mathrm{dynes} / \mathrm{cm}^{2}$. Photocells and associated equipment were used to record two response measures. Start tıme was defined as the tıme (in seconds) elapsing from the release of the trapdoor untıl interruption of the first photobeam located $31.8 \mathrm{~cm}$ from the rear of the startbox. Prepunishment tıme was defined as the time elapsing from the interruption of the first photobeam until the interruption of a second beam $61 \mathrm{~cm}$ from the rear of the startbox, in extinction, this score was the amount of time punıshed rats spent in the first $29.2 \mathrm{~cm}$ of the alley immediately pror to the punishment region.

\section{Procedure}

The experımenter admınıstered pretraining, escape trainıng (acquistion), and extinction treatment to each rat in a single session. In pretraining, the animal was first handled for $3 \mathrm{~min}$. This was followed by $3 \mathrm{~min}$ of confinement in the goalbox. After another $3 \mathrm{~min}$ of handling, the rat was permitted to explore the startbox floor and alley for $3 \mathrm{~min}$ prior to the beginning of escape trainıng.

Each of 20 escape training trials began when the rat was placed into the upper compartment of the startbox After $5 \mathrm{sec}$, the trapdoor was released and the startbox floor and alley were electrified. Rats could termınate shock by runnıng to the safe goalbox, where they spent the intertral interval of $30 \mathrm{sec}$. The no-tone and novel-tone groups were treated identically in acquisition. The safety signal subgroup received a 10 -sec presentation of the tone immediately upon entrance into the goalbox.

Extinction trials were begun after the last escape trial. Nonpunished (NP) rats no longer received shock in any part of the apparatus. Punished $(P)$ rats encountered shock only in the middle $61 \mathrm{~cm}$ of the alley. Groups NP-N (no tone) and P-N were typical nonpunished control and punished groups, respectively. Groups NP-NT (novel tone) and P-NT now received the tone in the startbox; the tone was turned on as the rat was placed onto the trapdoor, and it remained on until the subject broke the first photobeam $31.8 \mathrm{~cm}$ from the rear of the startbox. Groups NP-SS (safety signal) and P-SS continued to receive the $10-\mathrm{sec}$ tone in the goalbox and, in addition, experienced it in the startbox in the same manner as did the novel-tone groups. Each rat was tested for 75 extunction trials or untıl it failed to break the second photobeam within 30 sec on three consecutive trials.

\section{RESULTS}

For data analyses, the acquisition and extinction trials were divided into blocks of five trials and the median reciprocal start time (referred to as start speed) and median prepunishment speed in each block were used as the basic response measures for each rat. The groups were comparable during acquisition on both start and prepunishment speeds (Fs $<1.6)$.

Start speeds over the 15 extinction trial blocks are presented in Figure 1. The standard P-N group is seen to be considerably more resistant to extinction than the other groups. A 2 by 3 by 15 analysis of variance yielded only significant effects of trial blocks $(F=21.49, \mathrm{df}=14 / 924, \mathrm{p}<.001)$, NP vs. $\mathrm{P}$ by Trial Blocks $(F=2.27, d f=14 / 924, p<.025)$, and NP vs $P$ by Tone Condition $(F=3.23$, df $=$ $2 / 66, p<.05)$. This latter interaction indicates that the effects of punishment depended upon the tone condition. Analysis of the simple effects of punishment at each of the tone conditions showed that Group P-N ran significantly faster than did NP-N, i.e., self-punitive running $(F=6.41$, $d f=1 / 66$, $p<.025$ ). However, both the novel tone and safety signal treatments eliminated self-punitive running (NP-NT vs. P-NT, F $=1.37$, and NP-SS vs. P-SS, $F=1.06)$. Although inspection of Figure 1 suggests that the novel-tone condition led to more selfpunitive running than did the safety signal one, a 2 by 2 by 15 analysis of variance that included only these two conditions offered no statistical support for differential effectiveness of these two treatments.

Prepunishment speeds, presented in Figure 2, reflect a pattern that is very similar to that seen in the start speeds. The P-N group again shows more resistance to extinction than the other groups. The analysis of variance of these scores yielded significant main effects of punishment $(F=5.60, \mathrm{df}=$ $1 / 66, p<.025)$ and trial blocks $(F=36.81, d f=$ $14 / 924, p<.001$ ), as well as a significant interaction of these two variables $(F=2.26$, df $=14 / 924$, $p<.025)$. The Punishment by Tone interaction was not significant $(F=1.21)$; however, analysis of the simple effects of punishment under each tone condition were planned comparisons that were conducted. Self-punitive running was found under the no-tone condition $(F=6.18$, df $=1 / 66, p<.025)$. The punished groups did not run significantly faster than the nonpunished groups (elimination of self-punitive behavior) with either novel tone $(F=1.76)$ or safety signal $(F<1)$ treatment. A 2 by 2 by 15 analysis of variance revealed statistically equivalent effectiveness of the novel tone and safety signal treatments in reducing self-punitive running. 


\section{DISCUSSION}

The present results clearly indicate that the noveltone and safety signal treatments attenuated selfpunitive running. This conclusion follows from the empirical definition of self-punitive behavior given in the introduction. That is, under both novel-tone and safety signal treatment, shock punishment was not less effective than nonpunishment in extinguishing the escape response. In other words, the greater resistance to extinction produced by punishment under "standard" conditions (Groups NP-N and P-N) was prevented when the novel stimulus and safety signal were presented in the startbox.

The effectiveness of the novel tone supports the conclusion of Baum and Gordon (1970) and Henderson (1973) that certain stimuli can attenuate aversively motivated behavior in the absence of any prior conditioning. The process through which the novel tone affected self-punitive running remains unclear. Its influence does support the MowrerBrown hypothesis, which emphasizes the role of fear in motivating the behavior. Following Baum and Gordon (1970), it might be postulated that the tone evoked relaxation which competed with fear, although these authors admit that a relaxational analysis is rather incomplete at present.

Alternatively, the effect of the novel tone could have resulted from a distraction or stimulus change Istimulus generalization decrement) process that served to alter the stimuli controlling the running response. However, there are two problems with this interpretation. First, Henderson (1973, Experiment 2) provided convincing data in support of the hypothesis that novel tones are unconditional fear inhibitors rather than merely distracters. Second, a distraction interpretation of the present findings finds it difficult to account for the differential effect of the tone on nonpunished and punished rats.

Safety signal treatment produced results consistent with the Mowrer-Brown hypothesis and with demonstrated effects of safety signals on other types of fearmotivated behavior. However, the process underlying safety signal treatment perhaps is more unclear than is the one underlying novel-tone treatment given (a) the statistical equivalence of noveltone and safety signal treatment and (b) Henderson's (1973) warning that purported demonstrations of conditional safety signal effects must verify that unconditional stimulus effects cannot account for the alleged conditional effects. As such, the results of the safety signal treatment in the present experiment justify no explanatory concepts other than those postulated for the novel-tone treatment (e.g., relaxation, distraction).

In conclusion, the present results are encouraging in that they identify two ways of eliminating self-

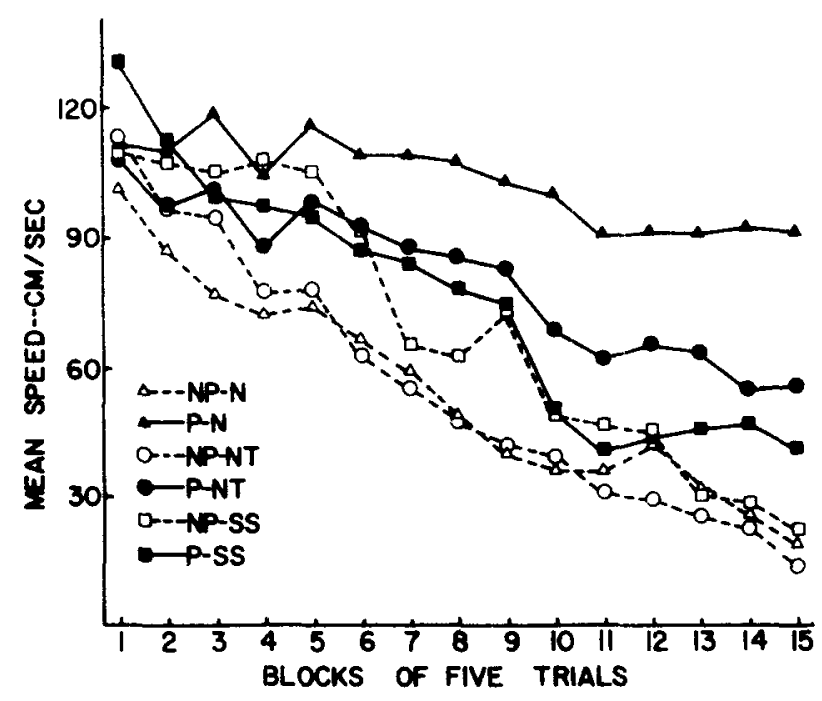

Figure 2. Mean prepunishment speed, over blocks of five extinction Irials.

punitive behavior. In addition to seeking new methods, future research should be directed toward empirical and theoretical analyses of the novel-tone and safety signal treatments. For example, independent measurement of fear in the startbox (Klare, 1974) would be one way of testing the above-noted implication of these findings for the Mowrer-Brown analysis of self-punitive behavior.

\section{REFERENCES}

Baum, M., \& Goroon, A. Effect of a loud buzzer applied during response prevention (flooding) in rats. Behaviour Research and Therapy, 1970, 8. 287.292.

Bolles, R. C. d Moot. S. A. Derived motives. Ammual Reve'w of Psychology, 1972, 23, $51-72$

Brown. J S. Factors affecting selt-punitive locomotor behavior. In B A. Campbell \& R M. Church (Eds.). Pumshment and arerswe hehavior New York Appleton-Century-Crotts. 1969.

HENDERSON, $R$ W conditioned and unconditioned fear mbibution in rats Jommal of Comparatur and Physologacal Psichologv. 1973, 84, 554-561.

KiARE. W. F. Conditioned tear and postshock emotionality in vicious circle behawen of rats. Joumal of Comparatue and Phiselogical Psichologl. 1974. 87. 364-372.

Martin. R. C. Selt-punilive behavior. One way to stop 1 . Psichonomec Sornce, 1969, 14. 25-26.

Melvin. K. B. Vicious circle behavior. In H. D. Kinmel (Ed.). Experimental psichopathology Recent research and theory. New York: Academic Press. 1971

ONeIl. H. F.. Skeen, L. C., \& Ryan, F. I. Prevention of vicuus corcte behavor Journal of Comparane and Physological Pivelologl, 1970, 70, 281-285.

Walker. J. Williams. S., \& Martin, R. C. The eftects ot scist intedaction upon persistence of selt-punitue behavor. Bullown of the Prichomomuc Soctely, 1974, 2, 423-425.

Weisman. R. G. Denny, M R, Platt, S. A.. \& Zerbolio. D J Fachlation of cranctun be a stmulus associated with long nomstoch combintement penods Joumal of Comparatove

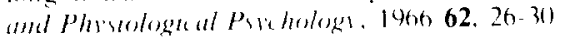

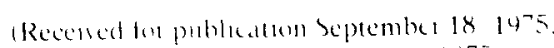
a
} 